\title{
USO DA GEOESTATÍSTICA NA AVALIAÇÃO DE VARIÁVEIS AMBIENTAIS EM GALPÃO DE SUÍNOS CRIADOS EM SISTEMA “WEAN TO FINISH” NA FASE DE TERMINAÇÃO
}

\section{BRENDA B. L. MEDEIROS ${ }^{1}$, DANIELLA J. DE MOURA ${ }^{2}$, JULIANA M. MASSARI ${ }^{3}$, THAYLA M. R. DE C. CURI ${ }^{4}$, ANA PAULA DE A. MAIA ${ }^{5}$}

RESUMO: O "wean to finish" é um sistema de criação de suínos que ainda é novo no Brasil, e não existem muitos estudos a respeito do ambiente onde estes animais são criados. Assim, o objetivo deste trabalho foi avaliar o ambiente térmico e aéreo por meio da técnica da geoestatística em galpão de suínos criados no sistema "wean to finish", na fase de terminação, nos horários das 09h, $12 \mathrm{~h}$ e $15 \mathrm{~h}$. A variabilidade dos atributos foi baseada na estatística descritiva dos dados de temperatura, umidade relativa, velocidade do ar, concentrações de amônia e dióxido de carbono, obtendo-se: média, mediana, coeficiente de variação, assimetria e curtose, com o teste de normalidade de Kolmogorov-Smirnov, através do programa estatístico Minitab 15. Para a determinação da existência ou não da dependência espacial, utilizou-se do exame de semivariograma, através do programa $\mathrm{GS}^{+}$, e, na elaboração dos mapas de distribuição espacial das variáveis, foi utilizado o programa Surfer. Os atributos de velocidade do ar e as concentrações dos gases $\mathrm{NH}_{3}$ e $\mathrm{CO}_{2}$ apresentaram alto coeficiente de variação devido aos dados serem heterogêneos, pois a instalação apresentava ventilação natural. O uso dos mapas de krigagem permitiu observar a diferença espacial da distribuição das variáveis avaliadas com diferentes números de animais/baia e em diferentes horários.

PALAVRAS-CHAVE: ambiência, distribuição espacial, mapas, suínos.

\section{USING GEOSTATISTICS TO EVALUATE THE ENVIRONMENT OF "WEAN TO FINISH"SWINE HOUSING}

\begin{abstract}
The "wean to finish" is a new pig production system in Brazil. To date, few research have investigated the environmental conditions of this pig farming system. The aim of this study was to evaluated the thermal environmental conditions and gases concentration using geostatistical techniques of a wean-to-finish barn during finishing phase at 9AM, 12PM e 3PM. The data variability was evaluated by the descriptive analysis, of the temperatures, relative humidity, air velocity, ammonia and carbon dioxide concentration. The results showed the average, median, coefficient of variation, asymmetry and curtosis and the Kolmogorov-Smirnov Test with the software Minitab 15. To determine the spatial dependence, the semivariogram exam was done, with the software $\mathrm{GS}^{+}$. The air velocity and gases concentration showed the highest coefficient of variation. This has happened because of the heterogeneity of the data caused by the natural ventilation. The Krigging maps showed the spacial differences of the pens with different numbers of animals in different hour of the day.
\end{abstract}

KEYWORDS: environmental control, spatial difference, maps, swine.

\footnotetext{
${ }^{1}$ Zootecnista, Dra ${ }^{a}$, Faculdade de Eng. Agrícola, UNICAMP/Campinas-SP, Fone: (19) 981013890, brendablmedeiros@ yahoo.com.br

${ }^{2}$ Eng $^{\circ}$ Agrônoma, Prof ${ }^{\text {a }}$. Dr ${ }^{\mathrm{a}}$, Faculdade de Engenharia Agrícola, UNICAMP/Campinas - SP, daniella.moura@ feagri.unicamp.br

${ }^{3}$ Médica Veterinária, Mestre, Faculdade de Engenharia Agrícola, UNICAMP/Campinas - SP, jujumassari@uol.com.br

${ }^{4}$ Eng $^{\mathbf{0}}$ Agrícola, Doutora, Faculdade de Engenharia Agrícola, UNICAMP/Campinas - SP, thaylamrcarvalho@ hotmail.com

${ }^{5}$ Zootecnista, Doutora, Faculdade de Engenharia Agrícola, UNICAMP/Campinas - SP, apa.maia@yahoo.com.br

Recebido pelo Conselho Editorial em: 4-10-2013

Aprovado pelo Conselho Editorial em: 17-3-2014
}

Eng. Agríc., Jaboticabal, v.34, n.5, p.800-811, set./out. 2014 


\section{INTRODUÇÃO}

$\mathrm{Na}$ produção convencional de suínos, normalmente os animais são criados em instalações separadas, conforme sua idade e categoria. Entretanto, atualmente, tem-se observado também um novo sistema no qual, nas fases de creche e terminação, os animais são criados em uma mesma instalação. Este manejo tem sido empregado para se ajustar às exigências ambientais, maximizar a utilização das instalações, diminuir a movimentação dos animais, consequentemente, diminuindo o estresse, e com isso, melhorar o bem-estar e o desempenho dos animais.

O sucesso na produção intensiva de animais está diretamente relacionado ao manejo eficiente do ambiente (NÄÄS, 2011) e depende da adequação das condições de conforto térmico dos animais alojados, devido à influência dos elementos meteorológicos que favorecem ou prejudicam seu desempenho (LIMA et al., 2011; SILVA et al., 2012).

Os fatores do ambiente térmico que mais impactam a produção de suínos são a temperatura do ar, umidade relativa, radiação e vento, podendo alterar o bem- estar animal (SOARES et al., 2009). Também é indispensável o controle da qualidade do ar nas instalações para suínos, pois este controle melhora os níveis de produtividade e diminuem os riscos de saúde (PANDORFI et al., 2012).

Desta forma, o conhecimento do ambiente criatório de uma instalação de suínos criados em sistema "wean to finish" é importante, pois os fatores climáticos e as concentrações de amônia e dióxido de carbono afetam o bem-estar e a produtividade dos animais.

Uma das maneiras de quantificar o bem-estar animal do ponto de vista térmico e aéreo seria a avaliação das variáveis de temperatura, umidade relativa e velocidade do ar, bem como a concentração de amônia e de dióxido de carbono que influencia na homeotermia e sanidade dos suínos. As condições climáticas apresentadas no interior da instalação são resultantes do manejo do sistema de ventilação e do sistema de aquecimento, bem como a tipologia da granja em que esses animais estão inseridos, as quais objetivam oferecer ambiente adequado para que o animal possa apresentar seu máximo desempenho produtivo (MARTIN, 2012).

Como forma de melhor avaliar o ambiente de produção animal, têm-se buscado o auxílio de métodos inovadores, ferramentas não invasivas de avaliação e controle do bem-estar em ambiente confinado (BORGES et al., 2010; CASTRO et al., 2011).

A geoestatística é uma ferramenta da estatística capaz de interpretar os resultados baseada na estrutura de sua variabilidade natural, utilizando a modelagem da dependência espacial das variáveis por meio da semivariância. Os mapas de variabilidade espacial de dados revelam que a análise de um único ponto de medição deve ser feita com cautela, para que um valor sub ou superestimado não seja relatado como uma condição representante do fenômeno em estudo. Neste sentido, a geoestatística permite o entendimento de fenômenos espaciais dentro de instalações para alojamento de animais mostrando as distribuições das variáveis ambientais (MILES et al., 2008; SILVA et al., 2013; SILVA NETO, 2011a; NÄ̈̈̈, 2011).

O uso desta ferramenta foi descrito em trabalhos para a avaliação da captação automática dos níveis de pressão sonora em instalações de creche de suínos, avaliação das condições iniciais de alojamento de aves em relação à qualidade da cama de frango reutilizada e do ar, em aviários comerciais de produção com diferentes sistemas de ventilação mínima, e o estudo de padrões espaciais de deposição de fezes por bovinos de corte em áreas de pastagem (BORGES et al., 2010; CARVALHO et al., 2011; SILVA NETO et al., 2011b). 
O objetivo deste trabalho foi avaliar o uso da técnica de geoestatística em galpão de suínos criados em sistema "wean to finish", na fase de terminação, nos horários das 09h, 12h e 15h.

\section{MATERIAL E MÉTODOS}

Este trabalho foi realizado na granja suinícola Hamilton Abatti, da Cooperativa Coperio - Rio dos Peixes, localizada na cidade de Joaçaba, Estado de Santa Catarina. A granja situa-se a 522 metros de altitude, na latitude $27^{\circ} 10^{\prime} 41^{\prime \prime}$ e longitude $51^{\circ} 30^{\prime} 17^{\prime}$ ', com a predominância do clima Cfa - Clima subtropical úmido pela classificação de Köppen. O experimento foi realizado de setembro de 2010 a fevereiro de 2011.

Para as avaliações, foram utilizadas 130 fêmeas da linhagem comercial (Large White X Agroceres).

Os animais foram alojados em galpão construído com paredes de alvenaria e madeira, pilares de concreto armado e madeira pinus, telhado de duas águas com cobertura de telhas de barro e beiral de $0,60 \mathrm{~m}$. O entorno da instalação era formado por grama com algumas árvores frutíferas (pessegueiros e macieira) que proporcionavam o sombreamento ao redor e dentro do galpão. $\mathrm{Na}$ instalação, havia no total 12 baias, com paredes separando as baias na altura de 1,00 $\mathrm{m}$, com blocos vazados, e cada baia possuía uma área de piso igual a 24,64 $\mathrm{m}^{2}(6,40 \mathrm{~m} \mathrm{X} \mathrm{3,85} \mathrm{m})$ de piso concretado e corredor de $0,95 \mathrm{~m}$ de largura no centro do galpão. Havia também duas baias auxiliares (ou baias-hospital) que possuem paredes de 1,00 $\mathrm{m}$ de altura, e cada baia possui uma área de piso igual a 4,89 $\mathrm{m}^{2}(1,27 \mathrm{~m} \mathrm{X} \mathrm{3,85} \mathrm{m).} \mathrm{O} \mathrm{pé-direito} \mathrm{era} \mathrm{de} 3 \mathrm{~m}$. Os fechamentos laterais eram de alvenaria, na altura de $1,30 \mathrm{~m}$, com blocos vazados e com cortinas com fechamento duplo. Em cada baia, havia um comedouro semiautomático, um bebedouro chupeta duplo e dois bebedouros tipo calha. $\mathrm{O}$ bebedouro do tipo chupeta duplo era regulado conforme a altura dos animais.

Os leitões foram alojados após o desmame, aos 28 dias, com o peso médio de 7,5 $\mathrm{kg}$ e foram abatidos com aproximadamente $120 \mathrm{~kg}$ de peso vivo, de 130 a 164 dias.

Os tratamentos que foram utilizados neste experimento (Figura 1): $\mathrm{T} 1=22$ animais e área disponível de $1,12 \mathrm{~m}^{2}$ animal $^{-1} ; \mathrm{T} 2=24$ animais e área disponível de $1,02 \mathrm{~m}^{2}$ animal $^{-1}$; $\mathrm{T} 3=26$ animais e área disponível de $0,94 \mathrm{~m}^{2}$ animal $^{-1}$; T4= 28 animais e área disponível de $0,88 \mathrm{~m}^{2}$ animal $^{-}$ 1; T5= 30 animais e área disponível de $0,82 \mathrm{~m}^{2}$ animal $^{-1}$. O experimento foi conduzido utilizando delineamento inteiramente casualizado.

Para as coletas de temperatura e velocidade do ar, foi utilizado o Termoanemômetro digital a fio quente, modelo 407123, marca Extech $^{\circledR}$. Para medir a umidade relativa do ar, foi utilizado o equipamento THDL 400, da marca Instrutherm ${ }^{\circledR}$. As medidas da concentração dos gases amônia $\left(\mathrm{NH}_{3}\right)$ e dióxido de carbono $\left(\mathrm{CO}_{2}\right)$ foram realizadas utilizando o equipamento GasAlertMicro 5$\mathrm{NH}_{3}$ e Gas Alert Micro 5 IR CO $\mathrm{CO}_{2}$, BW Technologies ${ }^{\circledR}$. Todas estas coletas foram realizadas em 3 horários diferentes (às $09 \mathrm{~h}, 12 \mathrm{~h}$ e $15 \mathrm{~h}$ ) no centro de cada baia, na altura de $1,50 \mathrm{~m}$.

Verificou-se a variabilidade dos atributos, baseada na estatística descritiva dos dados de temperatura do ar, umidade relativa do ar, velocidade do ar, concentrações de amônia e dióxido de carbono, obtendo-se: média, mediana, coeficiente de variação, assimetria e curtose, com o teste de normalidade de Kolmogorov-Smirnov. As análises de estatística descritiva destas variáveis foram realizadas através do programa estatístico MINITAB 15 (2007).

$\mathrm{Na}$ estatística descritiva, os valores elevados de coeficiente de variação (CV) podem ser considerados indicadores de heterogeneidade dos dados. Assim, de acordo com WARRICK e 
NIELSEN (1980), é considerada variabilidade baixa quando o coeficiente de variação apresentar valor abaixo de $12 \%$, variabilidade média com valores entre 12 e $24 \%$, e alta variabilidade quando os valores forem maiores que $24 \%$.

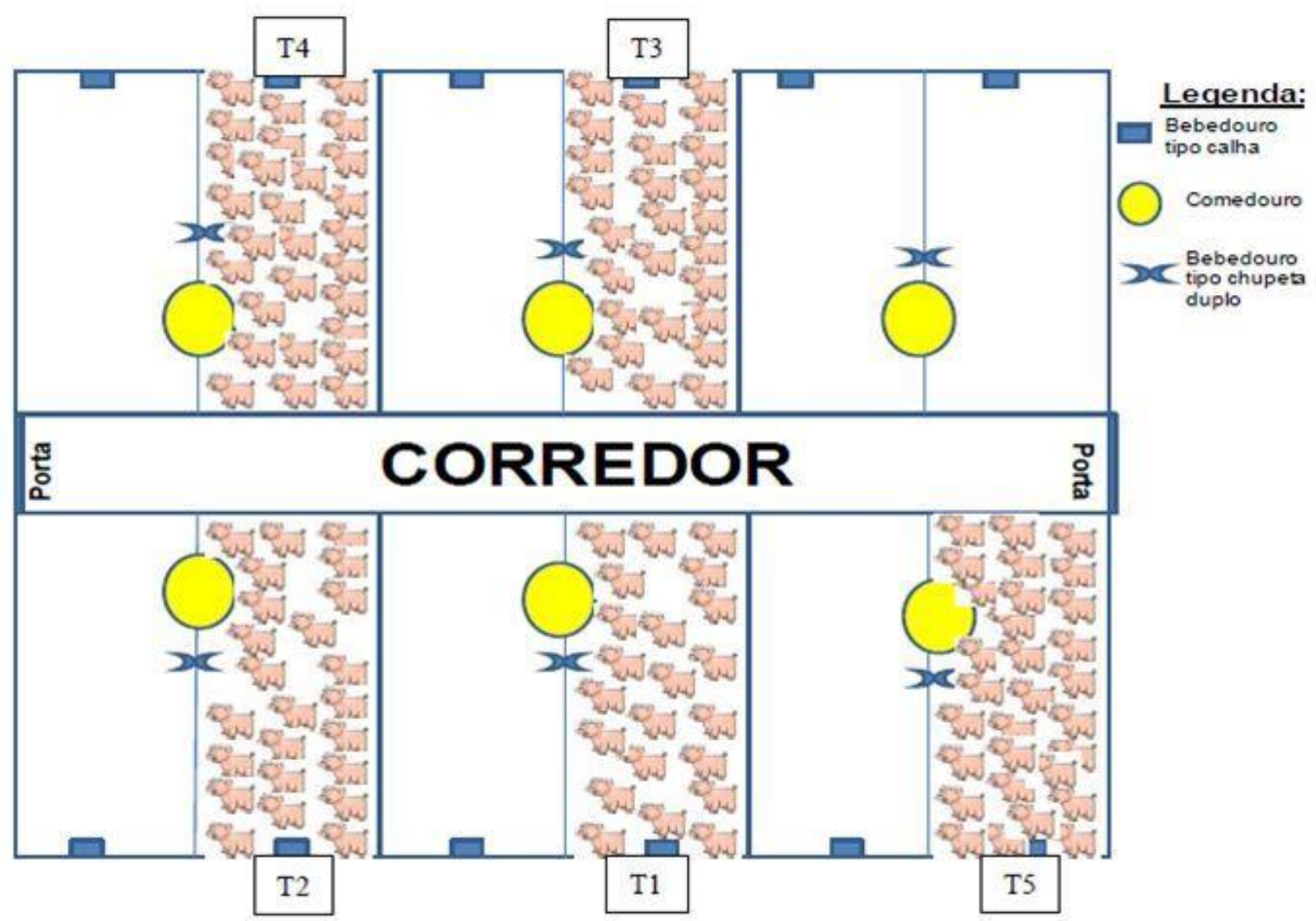

FIGURA 1. Representação ilustrativa do galpão e como os tratamentos foram divididos nas baias.

Schematic representation of pig farm and treatment arrangement among pens.

A dependência espacial foi avaliada por meio da geoestatística, conforme VIEIRA (2000). Os modelos de ajuste podem ser do tipo: com patamar (esférico, exponencial e gaussiano) e sem patamar (potência). Dos ajustes de modelo matemático aos valores calculados de $\gamma^{\text {(h) }}$,foram definidos os coeficientes do modelo teórico para o semivariograma (efeito pepita, $\mathrm{C}_{0}$; variância estrutural, $\mathrm{C}_{1}$; patamar, $\mathrm{C}_{0}+\mathrm{C}_{1}$; alcance, a). $\mathrm{O}$ efeito pepita refere-se ao valor da semivariância para distância zero e representa o componente da variação ao acaso; o patamar refere-se ao valor da semivariância em que curva estabiliza sobre um valor constante, e o alcance refere-se a distância da origem até onde o patamar atinge valores estáveis, expressando a distância além da qual as amostras não são correlacionadas (VIEIRA, 2000).

Para a análise do índice de dependência espacial (IDE), foi utilizada a relação $\mathrm{C} /\left(\mathrm{C}_{0}+\mathrm{C}_{1}\right)$, e os intervalos propostos: dependência espacial forte (IDE $<25 \%$ ); dependência moderada $(25 \leq$ IDE $<$ $75 \%$ ); dependência fraca (IDE $\geq 75 \%$ ) (CAMBARDELLA et al., 1994).

Para a determinação da existência ou não da dependência espacial, utilizou-se do exame de semivariograma, através do programa $\mathrm{GS}^{+}$(2004). Para elaboração dos mapas de distribuição espacial das variáveis avaliadas, foi utilizado o programa SURFER 9.0 (2009). 


\section{RESULTADOS E DISCUSSÃO}

A partir dos dados médios avaliados na fase de terminação (Tabela 1), observou-se que a temperatura obtida neste trabalho estava acima da condição considerada ideal para suínos em terminação, ou seja, acima de $21^{\circ} \mathrm{C}$ (KIEFER et al., 2010).

Houve distribuição assimétrica positiva para a maioria dos atributos. A assimetria negativa foi encontrada para umidade relativa do ar em todos os horários, concentração de amônia às $9 \mathrm{~h}$ e $12 \mathrm{~h}$ e concentração de dióxido de carbono às $12 \mathrm{~h}$ e às $15 \mathrm{~h}$.

TABELA 1. Estatística descritiva para as variáveis ambientais em galpão de suínos criados em sistema "wean to finish", nos diferentes horários da fase de terminação. Descriptive statistics for environmental data collected from wean-to-finish facility during finishing phase.

\begin{tabular}{|c|c|c|c|c|c|c|c|}
\hline Variáveis & Horários & Média & Mediana & $\mathrm{CV}$ & Curtose & Assimetria & $\begin{array}{c}\text { Teste } \\
\text { Kolmogorov- } \\
\text { Smirnov }\end{array}$ \\
\hline \multirow{3}{*}{$\begin{array}{c}\text { Temperatura } \\
\text { do ar }\left({ }^{\circ} \mathrm{C}\right)\end{array}$} & 09h & 25,70 & 25,62 & 6,23 & 2,62 & 1,21 & $0,13^{\mathrm{ns}}$ \\
\hline & $12 \mathrm{~h}$ & 28,40 & 28,10 & 4,86 & $-0,11$ & 0,68 & $0,10^{\mathrm{ns}}$ \\
\hline & $15 \mathrm{~h}$ & 29,47 & 29,35 & 6,63 & 0,09 & 0,25 & $0,11^{\mathrm{ns}}$ \\
\hline \multirow{3}{*}{$\begin{array}{c}\text { Umidade } \\
\text { relativa do ar } \\
(\%)\end{array}$} & $09 \mathrm{~h}$ & 56,67 & 57,40 & 6,71 & 3,29 & $-1,31$ & $0,09^{\mathrm{ns}}$ \\
\hline & $12 \mathrm{~h}$ & 44,32 & 45,17 & 12,13 & $-0,70$ & $-0,66$ & $0,13^{\mathrm{ns}}$ \\
\hline & $15 \mathrm{~h}$ & 40,44 & 42,62 & 18,71 & $-1,18$ & $-0,11$ & $0,13^{\mathrm{ns}}$ \\
\hline \multirow{3}{*}{$\begin{array}{l}\text { Velocidade do } \\
\operatorname{ar}\left(\mathrm{m} \mathrm{s}^{-1}\right)\end{array}$} & $09 \mathrm{~h}$ & 0,12 & 0,10 & 114,34 & 1,83 & 1,34 & $0,11^{\mathrm{ns}}$ \\
\hline & $12 \mathrm{~h}$ & 0,20 & 0,10 & 114,05 & 0,35 & 1,01 & $0,18^{\mathrm{ns}}$ \\
\hline & $15 \mathrm{~h}$ & 0,09 & 0,00 & 162,34 & 3,51 & 0,79 & $0,24^{\mathrm{ns}}$ \\
\hline \multirow{3}{*}{$\begin{array}{l}\mathrm{NH}_{3} \\
(\mathrm{ppm})\end{array}$} & $09 \mathrm{~h}$ & 1,66 & 2,00 & 54,60 & $-0,42$ & $-0,40$ & $0,08^{\mathrm{ns}}$ \\
\hline & $12 \mathrm{~h}$ & 1,44 & 1,50 & 61,41 & $-0,45$ & 0,06 & 0,02 \\
\hline & $15 \mathrm{~h}$ & 1,15 & 1,00 & 83,39 & $-0,93$ & 0,26 & $0,08^{\mathrm{ns}}$ \\
\hline \multirow{3}{*}{$\begin{array}{c}\mathrm{CO}_{2} \\
(\mathrm{ppm})\end{array}$} & $09 \mathrm{~h}$ & 214,03 & 200,00 & 64,43 & 16,14 & 2,35 & $0,12^{\mathrm{ns}}$ \\
\hline & $12 \mathrm{~h}$ & 106,63 & 150,00 & 82,75 & 2,76 & 0,81 & $0,14^{\mathrm{ns}}$ \\
\hline & $15 \mathrm{~h}$ & 134,56 & 150,00 & 71,11 & 3,38 & 1,85 & $0,13^{\mathrm{ns}}$ \\
\hline
\end{tabular}

$\mathrm{CV}(\%)=$ coeficiente de variação; ns=não significativo pelo teste de Kolmogorov-Smirnov.

Quando os valores da média e mediana estão próximos, os dados apresentam ou aproximam-se na distribuição normal. Assim, foi possível observar que as variáveis temperatura do ar às 09h e $15 \mathrm{~h}$, umidade relativa do ar às $15 \mathrm{~h}$, velocidade do ar às $12 \mathrm{~h}$ e concentração de amônia às $15 \mathrm{~h}$ apresentaram valores próximos em relação à média e à mediana, caracterizando distribuição simétrica. Para as demais variáveis, os valores de média e mediana estavam distantes.

Para umidade relativa do ar, os valores médios preconizados por KIEFER et al. (2010) e ORLANDO et al. (2006) são de 70\%, sendo que valores menores que $40 \%$ e maiores que $90 \%$ são considerados críticos.

A velocidade do ar apresentou os maiores valores do coeficiente de variação, seguidos das concentrações de $\mathrm{NH}_{3}$ e $\mathrm{CO}_{2}$. Em relação à velocidade do ar, resultados semelhantes foram verificados por FARIA et al. (2008), uma vez que a alta variabilidade se deve ao vento ser caracterizado por mudar de magnitude e direção constantemente, com variações de até $100 \%$ na 
média da magnitude, num intervalo de 5 minutos, o que justifica o valor alto de CV obtido para esta variável. Assim como no estudo de PAULO et al. (2009), os níveis de amônia encontrados nas instalações não tendem a causar consequências mais graves aos animais, por estarem abaixo dos níveis críticos.

O coeficiente de variação teve baixa variabilidade para temperatura e umidade relativa do ar, em todos os horários. Conforme WARRICK e NIELSEN (1980), a variabilidade é considerada baixa quando o coeficiente de variação apresentar valor abaixo de $12 \%$, variabilidade média com valores entre 12 e $24 \%$, e alta variabilidade quando os valores forem maiores que $24 \%$.

Para a maioria das variáveis estudadas, a assimetria e a curtose apresentaram distribuição normal, ou seja, com valores próximos a zero, com exceção do atributo da concentração de dióxido de carbono às $09 \mathrm{~h}$.

Os resultados obtidos com o teste de normalidade de Kolmogorov-Smirnov foram apenas para umidade relativa do ar às $9 \mathrm{~h}$ e concentração de amônia em todos os horários.

A partir dos resultados da análise geoestatística (modelos e parâmetros estimados dos semivariogramas), foi observada dependência espacial para todas as variáveis estudadas (Tabela 2).

TABELA 2. Modelos e parâmetros estimados dos semivariogramas experimentais para as variáveis ambientais, nos diferentes horários da fase de terminação. Estimated models and parameters of semivariogram for environmental variables during finishing phase.

\begin{tabular}{ccccccccc}
\hline \multirow{2}{*}{ Variáveis } & \multirow{2}{*}{ Horários } & Modelo & $\begin{array}{c}\text { Efeito } \\
\text { Pepita }\end{array}$ & Patamar & Alcance & GDE & $\mathrm{R}^{2}$ & SQR \\
\hline \multirow{2}{*}{ Temperatura do ar } & $9 \mathrm{~h}$ & Exponencial & 0.01 & 0.09 & 7.29 & 11.11 & 0.76 & $2.61 \mathrm{E}-04$ \\
$\left({ }^{\circ} \mathrm{C}\right)$ & $12 \mathrm{~h}$ & Esférico & 0.02 & 0.18 & 7.14 & 8.33 & 0.91 & $1.64 \mathrm{E}-03$ \\
& $15 \mathrm{~h}$ & Esférico & 0.08 & 0.82 & 6.89 & 9.44 & 0.93 & $2.40 \mathrm{E}-02$ \\
\hline Umidade relativa do & $9 \mathrm{~h}$ & Esférico & 0.11 & 2.84 & 4.23 & 3.87 & 0.97 & $8.62 \mathrm{E}-03$ \\
$\operatorname{ar}(\%)$ & $12 \mathrm{~h}$ & Exponencial & 0.54 & 1.31 & 27.93 & 41.22 & 0.91 & $5.60 \mathrm{E}-02$ \\
& $15 \mathrm{~h}$ & Esférico & 0.20 & 3.62 & 3.22 & 5.52 & 0.78 & $6.09 \mathrm{E}-01$ \\
\hline \multirow{2}{*}{ Velocidade do ar $(\mathrm{m}$} & $9 \mathrm{~h}$ & Exponencial & 0.00 & 0.01 & 4.41 & 10.00 & 0.76 & $4.97 \mathrm{E}-06$ \\
$\left.\mathrm{~s}^{-1}\right)$ & $12 \mathrm{~h}$ & Exponencial & 0.01 & 0.03 & 6.45 & 14.71 & 0.68 & $1.27 \mathrm{E}-04$ \\
& $15 \mathrm{~h}$ & Gaussiano & 0.00 & 0.02 & 3.45 & 23.33 & 0.82 & $2.41 \mathrm{E}-05$ \\
\hline \multirow{2}{*}{$\mathrm{NH}_{3}(\mathrm{ppm})$} & $9 \mathrm{~h}$ & Esférico & 0.02 & 0.46 & 3.73 & 4.11 & 0.86 & $7.34 \mathrm{E}-03$ \\
& $12 \mathrm{~h}$ & Esférico & 0.08 & 0.60 & 7.97 & 12.83 & 0.79 & $5.43 \mathrm{E}-02$ \\
& $15 \mathrm{~h}$ & Esférico & 0.12 & 0.58 & 10.61 & 20.72 & 0.78 & $5.58 \mathrm{E}-02$ \\
\hline \multirow{2}{*}{$\mathrm{CO}_{2}(\mathrm{ppm})$} & $9 \mathrm{~h}$ & Esférico & 400.00 & 6334.00 & 4.00 & 6.32 & 0.79 & $2.40 \mathrm{E}+06$ \\
& $12 \mathrm{~h}$ & Esférico & 360.00 & 6037.00 & 4.23 & 5.96 & 0.93 & $7.72 \mathrm{E}+05$ \\
& $15 \mathrm{~h}$ & Esférico & 690.00 & 6913.00 & 7.13 & 9.98 & 0.92 & $2.12 \mathrm{E}+06$ \\
\hline
\end{tabular}

GDE= valor percentual do grau de dependência espacial; $\mathrm{R}^{2}=$ coeficiente de determinação; $\mathrm{SQR}=$ Soma dos quadrados dos resíduos; $\mathrm{NH}_{3}=$ concentração de amônia; $\mathrm{CO}_{2}=$ concentração de dióxido de carbono

Os semivariogramas que se ajustaram ao modelo gaussiano foram apenas da velocidade do ar às 15h. Para o modelo exponencial, foram: temperatura às $09 \mathrm{~h}$, umidade relativa do ar às $12 \mathrm{~h}$, velocidade do ar às $09 \mathrm{~h}$ e $12 \mathrm{~h}$. Os demais atributos foram classificados como modelo esférico. Semelhantemente aos resultados obtidos por SILVA et al. (2012), que estudaram condições térmicas em ambiente de pré-ordenha de bovinos de leite, também foi obtida semivariograma mais bem ajustado ao modelo esférico para a temperatura do ar. 


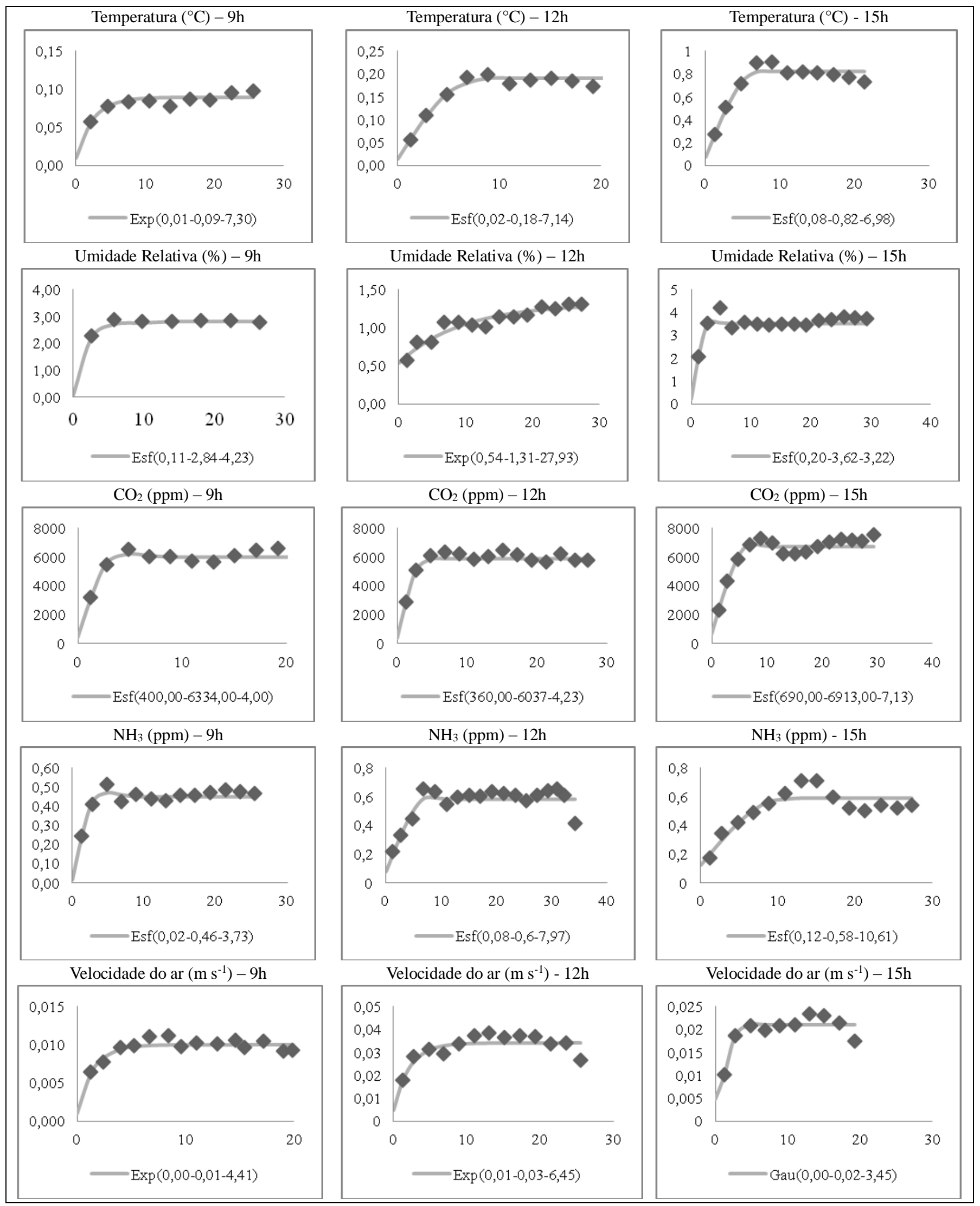

FIGURA 2. Mapas de Krigagem para as variáveis ambientais de temperatura $\left({ }^{\circ} \mathrm{C}\right)$, umidade relativa $(\%)$, concentrações de $\mathrm{CO}_{2}$ e $\mathrm{NH}_{3}$ (ppm) e velocidade do ar $\left(\mathrm{m} \mathrm{s}^{-1}\right)$, em galpão de suínos criados em sistema "wean to finish", na fase de terminação, no horário das 9h, 12h e 15h. Kriging Maps for temperature $\left({ }^{\circ} \mathrm{C}\right)$, relative humidity $(\%)$, levels of $\mathrm{CO}_{2}$ and $\mathrm{NH}_{3}(\mathrm{ppm})$ and air velocity $\left(\mathrm{m} \mathrm{s}^{-1}\right)$ in the wean-to-finish system during finishing phase, at 9AM, 12PM and 3PM. 
A análise da relação $\mathrm{C}_{0} /\left(\mathrm{C}_{0}+\mathrm{C}_{1}\right)$ mostrou grau de dependência moderada para o atributo de umidade relativa do ar às $12 \mathrm{~h}$. Os demais atributos mostraram grau de dependência espacial forte. Concordando com CARVALHO (2010), a distribuição das variáveis térmicas e aéreas no espaço não é aleatória, uma vez que todas as variáveis estudadas apresentaram grau de dependência espacial forte ou moderado. A avaliação da homogeneidade dos parâmetros climáticos é essencial para assegurar a qualidade do manejo do ambiente térmico e aéreo a fím de minimizar a ocorrência de regiões quentes e com pouca renovação de ar (pontos mortos), melhorando a qualidade e a produção do lote (BOURNET \& BOULARD, 2010).

O coeficiente de determinação $\mathrm{R}^{2}$ apresentou valores superiores a 0,68 nos modelos ajustados.

Para o alcance de dependência espacial, foi observada variação de 3,22 m para umidade relativa do ar às $15 \mathrm{~h}$ e de $27,93 \mathrm{~m}$ para umidade relativa do ar às $12 \mathrm{~h}$. As médias de alcance da umidade relativa do ar às $12 \mathrm{~h}$ e a concentração de amônia às $15 \mathrm{~h}$ foram superiores às demais médias, sendo muito boas, pois indicam que, para estes atributos, o raio de alcance foi maior, abrangendo mais espaço dentro do galpão. Segundo VIEIRA (2000), os pontos localizados numa área de raio igual ao alcance são mais homogêneos entre si quando comparados aos localizados fora desta área.

No mapa da temperatura do ar (Figura 3), pode-se observar que, na localização do galpão onde o sol batia no horário das 09h, obtiveram-se as maiores médias de temperatura. $\mathrm{Na}$ extremidade de baixo do mapa, também podem ser observadas as menores médias de temperatura do ar, podendo ser porque, nesta região, estão alojados os tratamentos com as menores quantidades de animais.

A umidade relativa do ar concentrou-se na região central da granja, sendo que nas laterais estavam os menores valores, o que pode ser devido a aberturas das cortinas da instalação. Este resultado também foi observado por CARVALHO et al. (2012) que apresentam a influência do ambiente externo no ambiente interno, sendo que, nas laterais onde ocorreram maiores temperaturas, foram observados menores níveis de umidade relativa.

A concentração de dióxido estava bem homogênea, com exceção da extremidade da porta de saída (extremidade de baixo do mapa) onde foi observada uma pequena ilha com valores mais altos. Já a concentração de amônia foi maior na região central do galpão e menor nas extremidades, podendo ser atribuídas às aberturas laterais e por as cortinas não estarem totalmente abertas. Na região central, pela menor renovação do ar, houve uma tendência a concentrar maior umidade relativa do ar e concentração de $\mathrm{NH}_{3}$. Esta correlação também foi observada no trabalho de CORKERY et al. (2013), que observaram que a concentração de amônia tem forte correlação com os níveis de umidade relativa (o valor de $\mathrm{R}^{2}$ oscilou entre 0,86 e 0,92 ); sendo assim, se a umidade relativa se mantiver em níveis adequados, a concentração de amônia também estará em concentrações adequadas.

De modo geral, a velocidade do ar neste mapa foi bem baixa, com exceção de algumas pequenas regiões que se formaram, onde foram mais altas. Apesar de a variação da velocidade do ar ser pequena, foi aleatória no interior do galpão, da mesma forma que ocorreu no trabalho de CARVALHO (2010), mostrando que houve desuniformidade na renovação de ar, podendo ser devido ao galpão receber ventilação natural. 


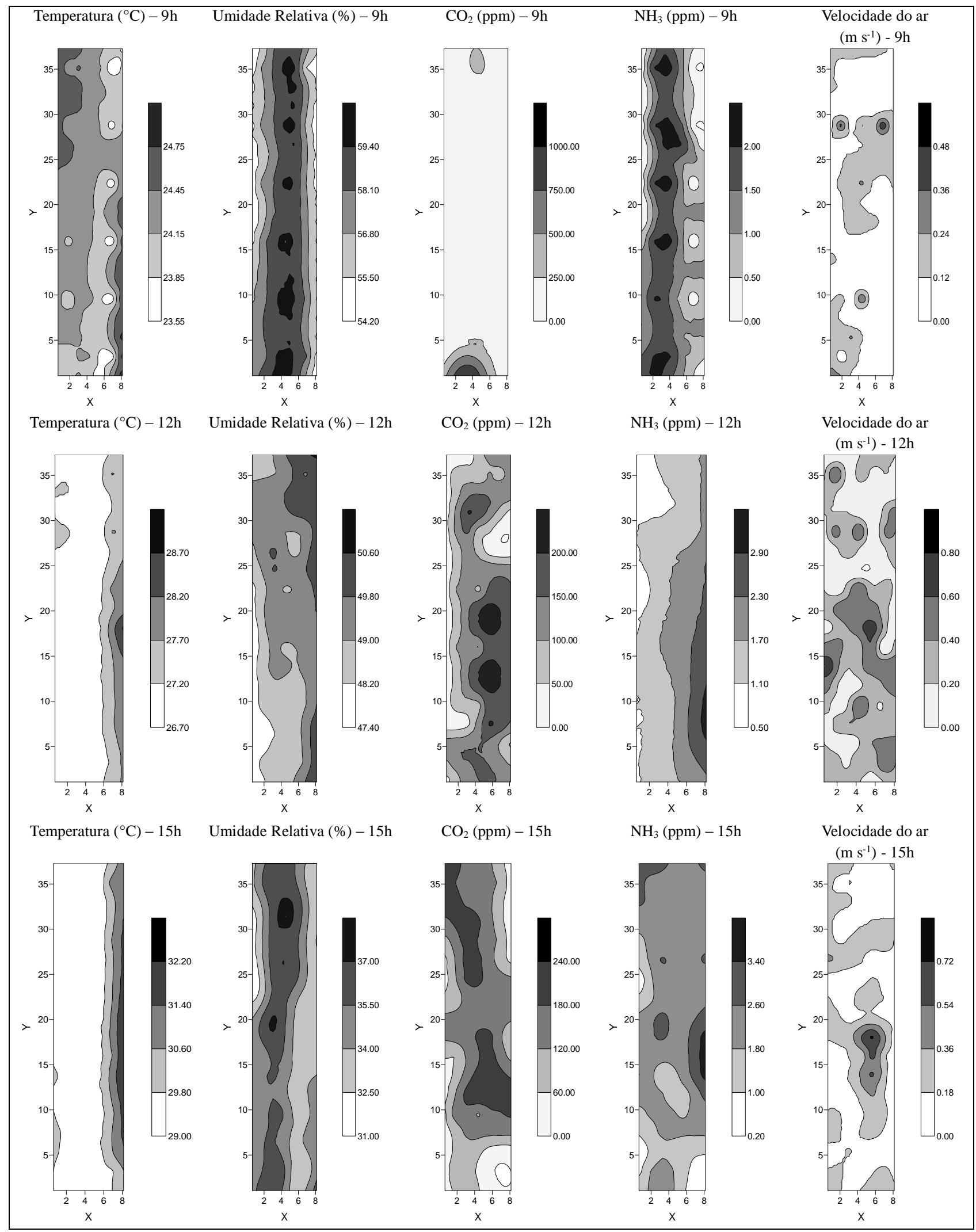

FIGURA 3. Mapas de Krigagem para as variáveis ambientais temperatura $\left({ }^{\circ} \mathrm{C}\right)$, umidade relativa (\%), concentrações de $\mathrm{CO}_{2} \mathrm{e} \mathrm{NH}_{3}$ (ppm) e velocidade do ar $\left(\mathrm{m} \mathrm{s}^{-1}\right)$, em galpão de suínos criados em sistema "wean to finish", na fase de terminação, no horário das $9 \mathrm{~h}$, $12 \mathrm{~h}$ e $15 \mathrm{~h}$. FIGURE 3. Kriging Maps for temperature $\left({ }^{\circ} \mathbf{C}\right)$, relative humidity $(\%)$, levels of $\mathrm{CO}_{2}$ and $\mathrm{NH}_{3}(\mathrm{ppm})$ and air velocity $\left(\mathrm{m} \mathrm{s}^{-1}\right)$ in the wean-to-finish system during finishing phase, at 9AM, 12PM and 3PM. 
Por uma avaliação geral dos mapas das $12 \mathrm{~h}$, pode-se observar que, do lado esquerdo da instalação, foram encontrados os menores valores das médias de temperatura, umidade relativa do ar, concentrações de amônia e dióxido de carbono. Na extremidade esquerda do mapa, no horário das $15 \mathrm{~h}$ o sol batia deste lado, fazendo com que a temperatura nesta região ficasse maior devido aos raios solares entrarem no galpão pela abertura das cortinas que permaneciam pela metade. Este fato é semelhante aos resultados obtidos por FARIA et al. (2008), que, avaliando galpão de confinamento de bovinos de leite, também obtiveram maiores valores de temperatura do ar, na região onde se incidiam os raios solares dentro do galpão.

Nesta face esquerda, também se podem observar as maiores médias da concentração dos gases $\mathrm{CO}_{2}$ e $\mathrm{NH}_{3}$, sendo que a produção de $\mathrm{CO}_{2}$ pelos animais está diretamente relacionada com sua produção de calor, ou seja, diretamente relacionada ao ambiente térmico (CAMPOS et al., 2009).

Assim como às 09h, a distribuição da velocidade do ar dentro do galpão foi heterogênea em toda a instalação.

O mapa da distribuição da temperatura foi homogêneo do lado esquerdo e na região central do galpão, na fase de terminação às $15 \mathrm{~h}$. A distribuição da umidade relativa e da concentração de dióxido de carbono foi maior na região central da instalação, indicando baixa renovação do ar, o que é confirmado pelos baixos valores médios da velocidade do ar (entre 0,00 e $0,80 \mathrm{~m} \mathrm{~s}^{-1}$ ), dificultando aos suínos a perda de calor por convecção (MARTIN, 2012).

\section{CONCLUSÃO}

No galpão onde os animais foram criados em sistema "wean to finish", nos diferentes horários avaliados, foi observada distribuição heterogênea de todas as variáveis estudadas, sendo destacadas a velocidade do ar e as concentrações dos gases.

Com o uso da técnica de geoestatística, foi possível definir as áreas onde ocorre a variabilidade espacial para as diferentes variáveis estudadas, mostrando-se, assim, a necessidade de controlar e corrigir problemas relacionados à instalação que recebe ventilação natural.

\section{AGRADECIMENTOS}

À FAPESP, pela concessão da bolsa de estudo, pela reserva técnica e pelo auxílio à pesquisa.

\section{REFERÊNCIAS}

BORGES, G.; MIRANDA, K. O. S.; RODRIGUES, V. C.; RISI, N. Uso da geoestatística para avaliar a captação automática dos níveis de pressão sonora em instalações de creche para suínos. Engenharia Agrícola, Jaboticabal, v. 30, n. 3, p. 377-385, jun. 2010.

BOURNET, P.E.; BOULARD, T. Effect of ventilator configuration on the distributed climate of greenhouses: A review of experimental and CFD studies. Computers and Electronics in Agriculture, New York, n. 74, p. 195-217, 2010.

CAMBARDELLA, C.A.; MOORMAN, T.B.; NOVAK, J.M.; PARKIN, T.B.; KARLEN, D.L.; TURCO, R.F.; KONOPKA, A.E. Field scale variability of soil properties in Central Iow a solis. Soil Science Society of America Journal, Madison, v. 58, n. 5, p.1501-1511, 1994.

CAMPOS, J. A.; TINÔCO, I. F. F; BAÊTA, F. C.; CECON, P. R.; MAURI, A. L. Qualidade do ar, ambiente térmico e desempenho de suínos criados em creches com dimensões diferentes.

Engenharia Agrícola, Jaboticabal, v.29, n.3, p.339-347, 2009. 
CARVALHO, T. M. R. Influência da ventilação mínima no ambiente térmico e aéreo na fase de aquecimento para frangos de corte. 2010. 140 f.. Dissertação (Mestrado em Engenharia Agrícola) Faculdade de Engenharia Agrícola, Universidade Estadual de Campinas, Campinas, 2010.

CARVALHO, T. M. R.; MOURA, D. J.; SOUZA, Z. M.; SOUZA, G. S.; BUENO, L. G. F. Qualidade da cama e do ar em diferentes condições de alojamento de frangos de corte. Pesquisa Agropecuária Brasileira, Brasília, v. 46, n. 4, p. 351-361, abr. 2011.

CARVALHO, T.M.R. et al. Use of geostatistics on broiler production for evaluation of different minimum ventilation systems during brooding phase. Revista Brasileira Zootecnia, Viçosa, MG, v.41, n.1, p.194-202, 2012.

CASTRO, J. O.; CAMPOS, A. T.; FERREIRA, R. A.; JÚNIOR, T. Y.; TADEU,H.C. Uso de ardósia na construção de celas de maternidade: I - efeito sobre o ambiente e comportamento de suínos.

Engenharia Agrícola, Jaboticabal, v. 31, n. 3, p. 458-467, 2011.

CORKERY, G. et al. Monitoring environmental parameters in poultry production facilities.

Computer Aided Process Engineering, CAPE Forum 2013. Graz: Graz University of Technology, 2013.

FARIA, F. F. MOURA, D. J.; SOUZA, Z .M.; MATARAZZO, S. V. Variabilidade espacial do microclima de um galpão utilizado para confinamento de bovinos de leite. Ciência Rural, Santa Maria, v. 38, n. 9, p. 2498-2505, 2008.

GAMMA DESIGN. GS+ - Geostatistics for the environmental sciences. Version 7.0. Michigan, 2004. 1 CD-ROM.

KIEFER, C.; MOURA, M.S.; SILVA, E.A.; SANTOS, A.P.; SILVA, C.M.; LUZ, M.F.; NANTES, C.L. Respostas de suínos em terminação mantidos em diferentes ambientes térmicos. Revista Brasileira Saúde Produção Animal, Salvador, v.11, n.2, p. 496-504, 2010.

LIMA, A. L.; OLIVEIRA, R. F. M.; DONZELE, J. L.; FERNANDES, H. C.; CAMPOS, PAULO H. R. F.; ANTUNES, M. V. L. Resfriamento do piso da maternidade para porcas em lactação no verão. Revista Brasileira de Zootecnia, Viçosa, MG, v. 40, n. 4, p. 804-811, 2011.

MARTIN, W.R. Effects of heat stress on thermoregulation, reproduction and performance of different parity sows. 2012. 154f. Thesis (Master of Science) - Faculty of the Graduate School University of Missouri, Missouri, 2012.

MINITAB. Minitab. Versão 15. 15.1. 2007.

MILES, D.M.; ROWE, D.E.; OWENS, P.R. Winter broiler litter gases and nitrogen compounds: Temporal and spatial trends. Atmospheric environment, Oxford, v. 42, n. 14, p. 3351-3363, 2008.

NÄÄS, I. A. Uso de técnicas de precisão na produção animal. Revista Brasileira de Zootecnia, v. Viçosa, MG, 40, n. 358-364, p. 358-364, 2011.

ORLANDO, U.A.D.; OLIVEIRA, R.F.M.; DONZELE, J.L.; FERREIRA, R.A.; SILVA, F.C.O.; VIEIRA VAZ, R.G.M.; SIQUEIRA, J.C. Níveis de proteína bruta e suplementação de aminoácidos em rações para leitoas mantidas em ambiente termoneutro dos 60 aos 100kg. Revista Brasileira de Zootecnia, Viçosa, MG, v.36, n.4, p. 1069 - 1075, 2007. Supl.

PANDORFI, H.; ALMEIDA, G. L. P.; GUISELINI, C. Zootecnia de precisão: princípios básicos e atualidades na suinocultura. Revista Brasileira de Saúde e Produção Animal, Salvador, v. 13, n. 2, p. 558-568, 2012.

PAUlO, R. M.; TINÔCO, I. F. F.; OLIVEIRA, P. A. V.; SOUZA, C. F.; BAÊTA, F. C.; CECON, P. R. Avaliação da amônia emitida de camas sobrepostas e piso concretado utilizados na criação de suínos. Revista Brasileira de Engenharia Agrícola e Ambiental, Campina Grande, v. 13 n. 2, p. ??, 2009. 
SILVA NETO, S. P.; SANTOS, A. C.; LEITE, R. L. L.; DIM, V. P.; CRUZ, R. S.; PEDRICO, A.; NETO, D. N. N. Análise espacial de parâmetros da fertilidade do solo em região de ecótono sob diferentes usos e manejos. Semina: Ciências Agrárias, Londrina, v. 32, n. 2, p. 541-552, 2011 b.

SILVA NETO, S. P.; SILVA, R. G.; SANTOS A.C.; GAMA, F. R.; GUERRA, M. S.S.; BRITO, M. J. D. Padrões espaciais de deposição de fezes por bovinos de corte em áreas de pastagem. Revista Brasileira de Saúde e Produção Animal, Salvador, v. 12, n. 2, p. 538-550, 2011 a.

SILVA, E.G.; SANTOS; A.C.; FERREIRA, C. L. S.; SOUSA, J. P. L.; ROCHA; J. M. L.;

SILVEIRA JÚNIOR, O. Variabilidade espacial das características ambientais e peso de frangos de corte em galpão de ventilação negativa. Revista Brasileira de Saúde e Produção Animal, Salvador, v. 14, n. 1, p. 132-141, 2013.

SILVA, I. M.; PANDORFI, H.; ALMEIDA, G. L. P.; GUISELINI, C.; CALDAS, A. M.; JACOB, A. L. Análise espacial das condições térmicas do ambiente pré-ordenha de bovinos leiteiros sob regimes de climatização. Revista Brasileira de Engenharia Agrícola e Ambiental, Campina Grande, v. 16, n. 8, p. 903-909, 2012.

SILVA-MIRANDA, K. O.; BORGES, G.; MENEGALE, V. L. C.; SILVA, I. J. O. Efeito das condições ambientais no nível de ruído emitido por leitões. Engenharia Agrícola, Jaboticabal, v. 32, n. 3, p. 1-11, 2012.

SOARES, E. A.; LEAL, A. F.; MALHEIROS FILHO, J. R.; CAMERINI, N. L.; NASCIMENTO, J. W. B., DERMEVAL, A. F. Zoneamento bioclimático para produção de suínos na maternidade no município de Areia - PB. Revista Educação Agrícola Superior, Brasília, v. 24, n. 1, p. 3-6, 2009.

SURFER, version 9.0. Contouring, gridding and surface mapping package for scientists an engineers. 2009. Disponível em: <http://www.goldesoftware.com>. Acesso em: 10 fev 2010.

VIEIRA, S. R. Geoestatística em estudos de variabilidade espacial do solo. In: NOVAIS, R. F. et al (Ed). Tópicos em ciência do solo. Viçosa: SBGS, 2000. v.1, cap.1, p.1-54.

WARRICK, A.W.; NIELSEN, D. R. Spatial variability of soil physical properties in the field. In: HILLEL, D., (ed). Applications of soil physics. New York, Academic Press, 1980. 350p. 